\title{
Design and development of a pneumatic switch assembly system based on PLC control technology
}

\author{
Li Yuxiao, Li Yujian \\ ${ }^{1}$ Binzhou Polytechnic, Binzhou 256600, China \\ ${ }^{2}$ Binzhou Municipal Highway Administration Bureau, Binzhou 256600, China
}

\begin{abstract}
In this paper, through analyzing the physical characteristics and function of the pneumatic switch, and through the simulation of drawing technology, the assembly module was designed based on PLC control system and I/O module. And its reliability has been proved by the experiment. The system obtained very good effects in actual productions.
\end{abstract}

Keywords: Switch assembly design, pneumatic switch, design.

\section{Introduction}

In recent years, with the rapid development of China's industrial economy, the need for automated equipment from the labor-intensive manufacturing has been highlighted by the tight labor market.

A programmable logic controller (PLC), or programmable controller is an industrial digital computer which has been ruggedized and adapted for the control of manufacturing processes, such as assembly lines, or robotic devices, or any activity that requires high reliability control and ease of programming and process fault diagnosis.

They were first developed in the automobile industry to provide flexible, ruggedized and easily programmable controllers to replace hard-wired relays, timers and sequencers. Since then they have been widely adopted as high-reliability automation controllers suitable for harsh environments. A PLC is an example of a "hard" real-time system since output results must be produced in response to input conditions within a limited time, otherwise unintended operation will result.

PLCs are well adapted to a range of automation tasks. These are typically industrial processes in manufacturing where the cost of developing and maintaining the automation system is high relative to the total cost of the automation, and where changes to the system would be expected during its operational life. PLCs contain input and output devices compatible with industrial pilot devices and controls; little electrical design is required, and the design problem centers on expressing the desired sequence of operations. PLC applications are typically highly customized systems, so the cost of a packaged PLC is low compared to the cost of a specific custom-built controller design. On the other hand, in the case of mass-produced goods, customized control systems are economical. This is due to the lower cost of the components, which can be optimally chosen instead of a "generic" solution, and where the non-recurring engineering charges are spread over thousands or millions of units.

For high volume or very simple fixed automation tasks, different techniques are used. For example, a cheap consumer dishwasher would be controlled by an electromechanical cam timer costing only a few dollars in production quantities.

A microcontroller-based design would be appropriate where hundreds or thousands of units will be produced and so the development cost (design of power supplies, input/output hardware, and necessary testing and certification) can be spread over many sales, and where the end-user would not need to alter the control. Automotive applications are an example; millions of units are built each year, and very few end-users alter the programming of these controllers. However, some specialty vehicles such as transit buses economically use PLCs instead of custom-designed controls, because the volumes are low and the development cost would be uneconomical.

In this paper, on the basis of the technology combined of pneumatic drive and stepping drive, and with PLC control technology as the core, the author, commissioned by a certain large-scale switch manufacturer, developed an assembling equipment for the switch functional parts, which could 
substitute the manual assembly of the switch button component, with the feeding and assembly of the cylindrical pin, the plastic button shell as well as the spring stopper included, thus the demand for labor in the company could be dramatically reduced, meanwhile, the labor productivity significantly improved and the benefit favorably increased.

\section{Working requirement of the equipment}

A pressure switch for sensing fluid pressure contains a capsule, bellows, Bourdon tube, diaphragm or piston element that deforms or displaces proportionally to the applied pressure. The resulting motion is applied, either directly or through amplifying levers, to a set of switch contacts. Since pressure may be changing slowly and contacts should operate quickly, some kind of over-center mechanism such as a miniature snap-action switch is used to ensure quick operation of the contacts. One sensitive type of pressure switch uses mercury switches mounted on a Bourdon tube; the shifting weight of the mercury provides a useful over-center characteristic.

The pressure switch may be adjustable, by moving the contacts or adjusting tension in a counterbalance spring. Industrial pressure switches may have a calibrated scale and pointer to show the set point of the switch. A pressure switch will have a differential range around its setpoint in which small changes of pressure do not change the state of the contacts. Some types allow adjustment of the differential.[1]

The pressure-sensing element of a pressure switch may be arranged to respond to the difference of two pressures. Such switches are useful when the difference is significant, for example, to detect a clogged filter in a water supply system. The switches must be designed to respond only to the difference and not to false-operate for changes in the common mode pressure.

The contacts of the pressure switch may be rated a few tenths of an ampere to around 15 amperes, with smaller ratings found on more sensitive switches. Often a pressure switch will operate a relay or other control device, but some types can directly control small electric motors or other loads.

Since the internal parts of the switch are exposed to the process fluid, they must be chosen to balance strength and life expectancy against compatibility with process fluids. For example, rubber diaphragms are commonly used in contact with water, but would quickly degrade if used in a system containing mineral oil.

Switches designed for use in hazardous areas with flammable gas have enclosure to prevent an arc at the contacts from igniting the surrounding gas. Switch enclosures may also be required to be weatherproof, corrosion resistant, or submersible.

An electronic pressure switch incorporates some variety of pressure transducer (strain gauge, capacitive element, or other) and an internal circuit to compare the measured pressure to a set point. Such devices may provide improved repeatability, accuracy and precision over a mechanical switch.

Pneumatic

Uses of pneumatic pressure switches include:

Switch a household well water pump automatically when water is drawn from the pressure tank.

Switching off an electrically driven gas compressor when a set pressure is achieved in the reservoir

Switching off a gas compressor, whenever there is no feed in the suction stage.

in-cell charge control in a battery

Switching on/off an alarm light in the cockpit of an aircraft if cabin pressure (based on altitude) is critically low.

Air filled hoses that activate switches when vehicles drive over them. Common for counting traffic and at gas stations.

The task for this equipment is to substitute the manual assembly of the switch button component, i.e. to assemble the switch button parts in Fig.1 (a) into the component shown in Fig.1 (b). 

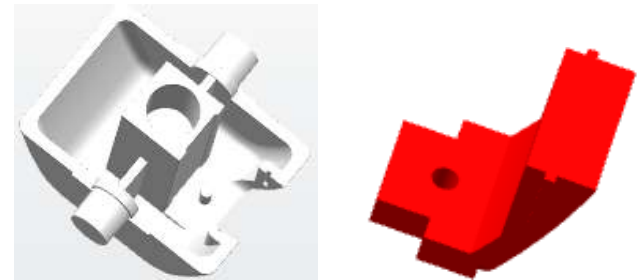

(a)Switch button parts

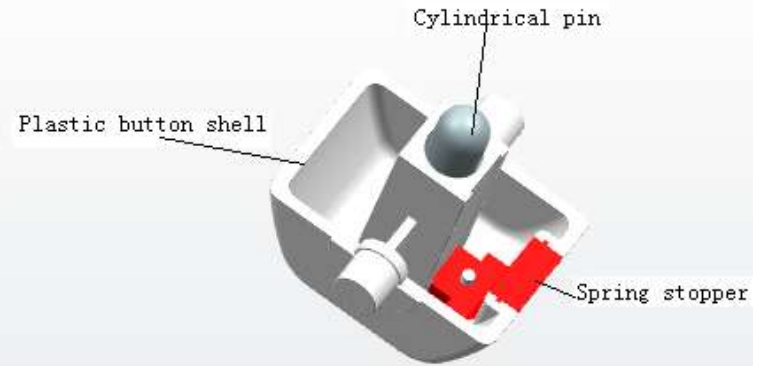

(b) Switch button component

Fig. 1 Switch button

\section{Equipment structure}

The equipment structure was modeled in Fig.2.The working principle of the equipment was analyzed as follows: the plastic button shell is fed to the loading guide by the vibrating disk 1 in a certain direction, which is then transferred to the work station on the rotary table by the feeding manipulator 10 , when the rotary table rotates for $90^{\circ}$, and subsequently, the spring stopper falls to the corresponding position of the plastic shell by the feeding manipulator 9 , again, the rotary table rotates for $90^{\circ}$, after that, the hot melt manipulator goes down to compact and assemble the spring stopper with the plastic shell, next, the rotary table rotates for $90^{\circ}$ again, and the charging manipulator for the cylindrical pin completes the assembly of the cylindrical pin and the plastic button shell, and then the rotary table rotates for another $90^{\circ}$, when the completely-assembled switch button component is placed on the charging guide by the feeding manipulator 5 , that is a complete operating cycle.

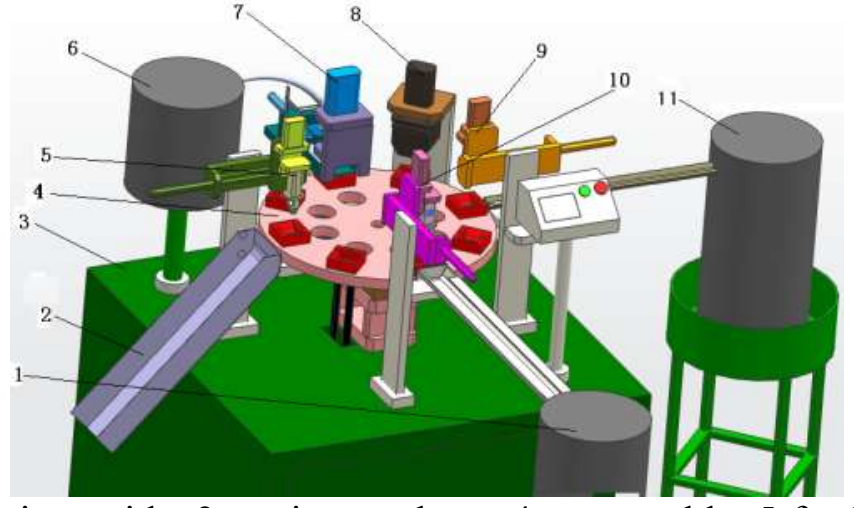

1-vibration disk 2-charging guide 3-equipment base 4-rotary table 5 -feeding manipulator for the switch button component 6-vibration disk 7-charging manipulator for the cylindrical pin 8-hot melt manipulator 9-feeding manipulator for the spring stopper 10-feeding manipulator for the plastic button shell 11-vibrating disc

Fig. 2 Structural modeling of the equipment

\section{Design of the pneumatic transmission system}

In accordance with the working requirement of the device, the motions of all the manipulators are achieved by a pneumatic system, with 14 circuits employed, which is composed of pneumatic FRL (filter, regulator and lubricator), exhaust valve, valve terminal, cylinder, rotating shaft, and motor, etc., thus the left-right movement, the lifting and dropping motions as well as the gripping and releasing actions can be realized

Working principle of the pneumatic system. The control principle diagram was shown in Fig.3, wherein 14 cylinders are employed, each with sensors designed and installed at the limiting positions, so that the position signals of each cylinder can be transferred into electrical signals and subsequently input into the PLC control system. Therein, YA1 YA14 are all electrically controlled reversing valves, and the motion direction control of each cylinder can be achieved through the output signals of the PLC control system. For the 14 pneumatic circuits share a similar principle, the feeding 
manipulator was here cited as an example for principle analysis: its left-right action as well as the lifting and dropping motions are constituted by two same circuits, and the lateral and vertical movements of the manipulator are realized by controlling of two single-acting cylinders through the two-position and five-way reversing valve in the valve terminal, with its movement speed regulated by the one-way throttle valve; moreover, its switching of the gripping and releasing movements are completed by a finger cylinder, whose motion direction and speed are controlled by the two-position and five-way valve and the one-way throttle valve in the valve terminal, respectively [4][5].

Cylinder design. The structural dimensions of the cylinder is directly associated with the operating mechanism of the host. After the work condition analysis, the load diagram preparation and the working pressure determination of each work condition, the dimensions and structures of the cylinders were determined based on the load, the moving velocity and working stroke, etc., which were then checked, and finally, the structural design of the cylinder was conducted, with the main dimensions as follows:

Inner diameter of the cylinder tube D: In the design, according to the cylinder thrust $\mathrm{F}$ and the selected working pressure $\mathrm{p}$, the inner diameter $\mathrm{D}$ could be determined as per the following formula, which ought to be rounded off by adopting a similar one in the standard [6].

$$
\frac{F}{\eta_{m}}=A_{1} p_{1}-A_{2} p_{2}, \quad A_{1}=\frac{F}{\eta_{m}\left(p_{1}-p_{2}\right)}, \quad D=\sqrt{\frac{4 A_{1}}{\pi}}
$$

Wherein $\eta_{m}$ is the mechanical efficiency of the cylinder; P1 and P2 are pressures of the head port and the rod port of the cylinder, respectively; A1 and A2 are working areas of the head port and the rod port, respectively.

Piston rod diameter $\mathrm{d}$ : The determination of the piston rod diameter $\mathrm{d}$ shall be designed to firstly meet the cylinder speed requirement, and then rounded off.

Cylinder tube lengths. It shall be designed depending on the maximum working stroke of each cylinder.

\section{PLC control system design}

This equipment, with PLC as the central controller, is required to accomplish the control of the rotary table and the pneumatic drive, etc., and its control system design is principally composed of I/O allocation and program development and design, etc.

$\mathrm{I} / \mathrm{O}$ address allocation.
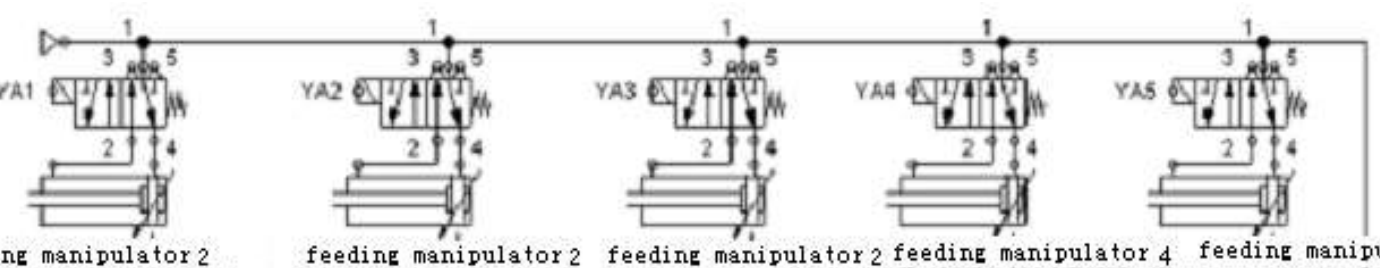

feeding manipulator 2 feeding manipulator 2 feeding manipulator 2 feedine manidulator 4 feeding manipulator 4 horizontal moving cylinder vertical moving cylinder eipper cylinder horizontal moving cylinder vertical moving cylinder

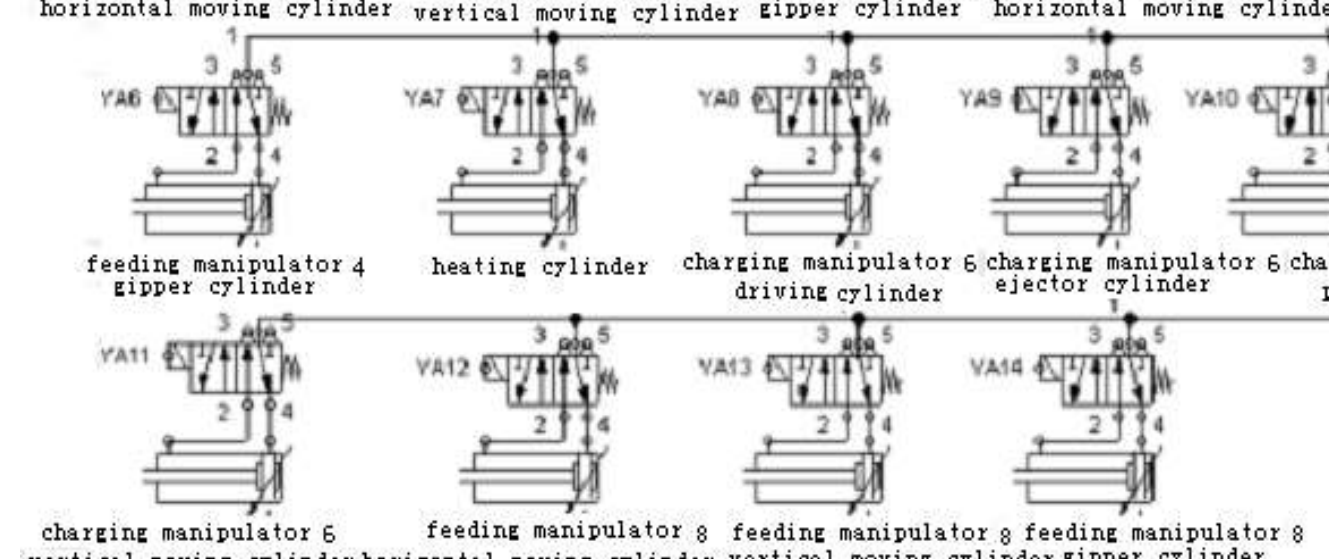

vertical moving cylinder horizontal moving cylinder vertical moving crlinder eidper cylinder

Fig. 3 working principle diagram of the pneumatic drive and control system 
The controlled variables required to be processed by this PLC system mainly include sensor signal processing, pneumatic component drive and stepping drive, etc., additionally, the $\mathrm{I} / \mathrm{O}$ allocation of PLC on the basis of hardware equipment was shown in Table 1.

Table $1 \mathrm{I} / \mathrm{O}$ allocation list

\begin{tabular}{|c|c|c|c|c|c|}
\hline \multicolumn{4}{|c|}{ Input signal } & \multicolumn{2}{|c|}{ Output signal } \\
\hline $\mathrm{X} 1$ & Start button & $\mathrm{X} 2$ & Stop button & Y0 & $\begin{array}{c}\text { Pulse count output } \\
\text { end of stepping } \\
\text { driver }\end{array}$ \\
\hline $\begin{array}{l}\mathrm{X} 3 \\
\stackrel{1}{\mathrm{X}} 10\end{array}$ & $\begin{array}{l}\text { Position sensors for } \\
\text { each cylinders of } \\
\text { feeding } \\
\text { manipulator } 2\end{array}$ & $\begin{array}{l}\text { X11 } \\
\text { X16 }\end{array}$ & $\begin{array}{l}\text { Position sensors } \\
\text { for each cylinders } \\
\text { of feeding } \\
\text { manipulator } 4\end{array}$ & Y1 & $\begin{array}{c}\text { Direction output } \\
\text { end of stepping } \\
\text { driver }\end{array}$ \\
\hline $\begin{array}{l}\mathrm{X} 17 \\
! \\
\times 20\end{array}$ & $\begin{array}{l}\text { Position sensors for } \\
\text { heating cylinder }\end{array}$ & $\begin{array}{l}\mathrm{X} 21 \\
\mid \\
\times 30\end{array}$ & $\begin{array}{l}\text { Position sensors } \\
\text { for each cylinders } \\
\text { of charging } \\
\text { manipulator } 6\end{array}$ & $\begin{array}{c}\mathrm{Y} 2 \\
\mid \\
\mathrm{Y} 17\end{array}$ & $\begin{array}{c}\text { Electric signals of } \\
\text { each } \\
\text { electromagnetic } \\
\text { valves }\end{array}$ \\
\hline $\begin{array}{l}\mathrm{X} 31 \\
! \\
\times 36\end{array}$ & $\begin{array}{l}\text { Position sensors for } \\
\text { each cylinders of } \\
\text { feeding } \\
\text { manipulator } 8\end{array}$ & X37 & $\begin{array}{l}\text { Element detection } \\
\text { sensor at shell feed }\end{array}$ & & \\
\hline
\end{tabular}

According to Table 1, Mitsubishi FX 3u-64MT PLC was selected, with its control circuit diagram shown in Fig.4. After accessed to the electrical control box, the three-phase 380V voltage was separated into two circuits through the power switch and the air switch, one three phase is supplied to the stepping driver through the transformer and the switching power supply, wherein $\mathrm{Y} 0$ and $\mathrm{Y} 1$ of the stepping driver are inputs of pulse and direction, respectively, A+, A-, B+ and B- are power inputs of the stepping motor; the other one is supplied to the Mitsubishi PLC and the heating rods through the transformer, with the detailed input and output definitions of PLC shown in Table 1 [2].

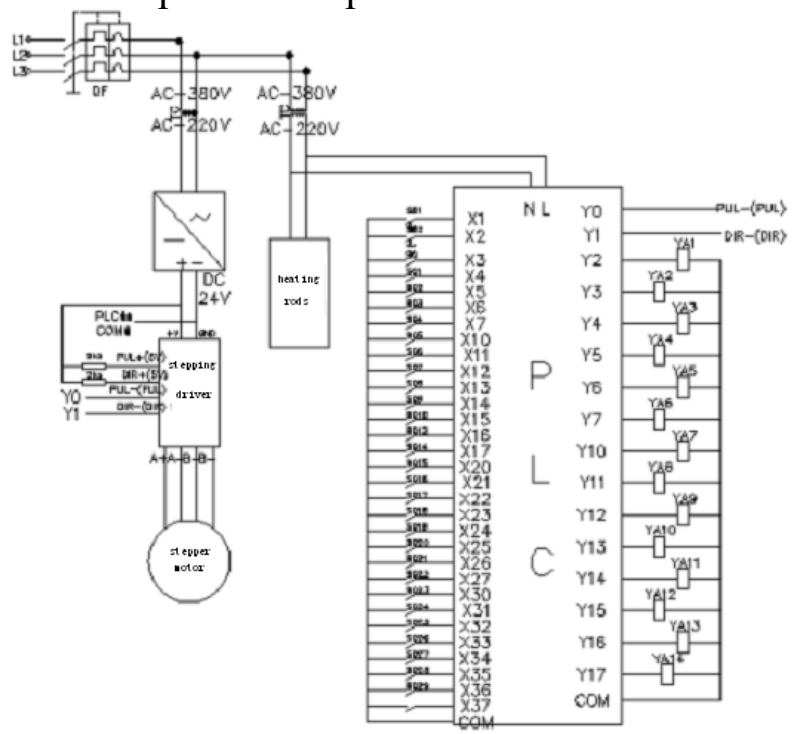

Fig. 4 PLC control circuit diagram

PLC program design.The PLC program of this assembling device includes two major control functions, i.e. start and stop. When the start button is pressed down, element can be detected by the material detection sensor at the feed for the plastic button shell, and then the manipulators 5, 7,9 and 10 as well as the holt-melt rods will start to work in the working sequence; while the stop button is pressed down, the device will shut down. The concrete programming idea was shown in Fig.5. 
As can be seen from the flowchart, its five working stations operate simultaneously, with one process at one station, after the tasks of each are all completed, the rotary table will rotate for an operating angle, when the five working stations will simultaneously start to work again; and when the stop button is pressed down, the device will shut down. When no material is detected, the equipment will not stop until the current workflow is accomplished.

\section{Conclusion}

The mechanical structure of this equipment was ingeniously designed, wherein the pneumatic drive system was employed to complete the power transmission, and the PLC control system was applied to achieve the automation design. Overall, it was practically proved to exhibit perfect functions and remarkable production benefit after putting into operation, through which automated production was eventually realized in the company.

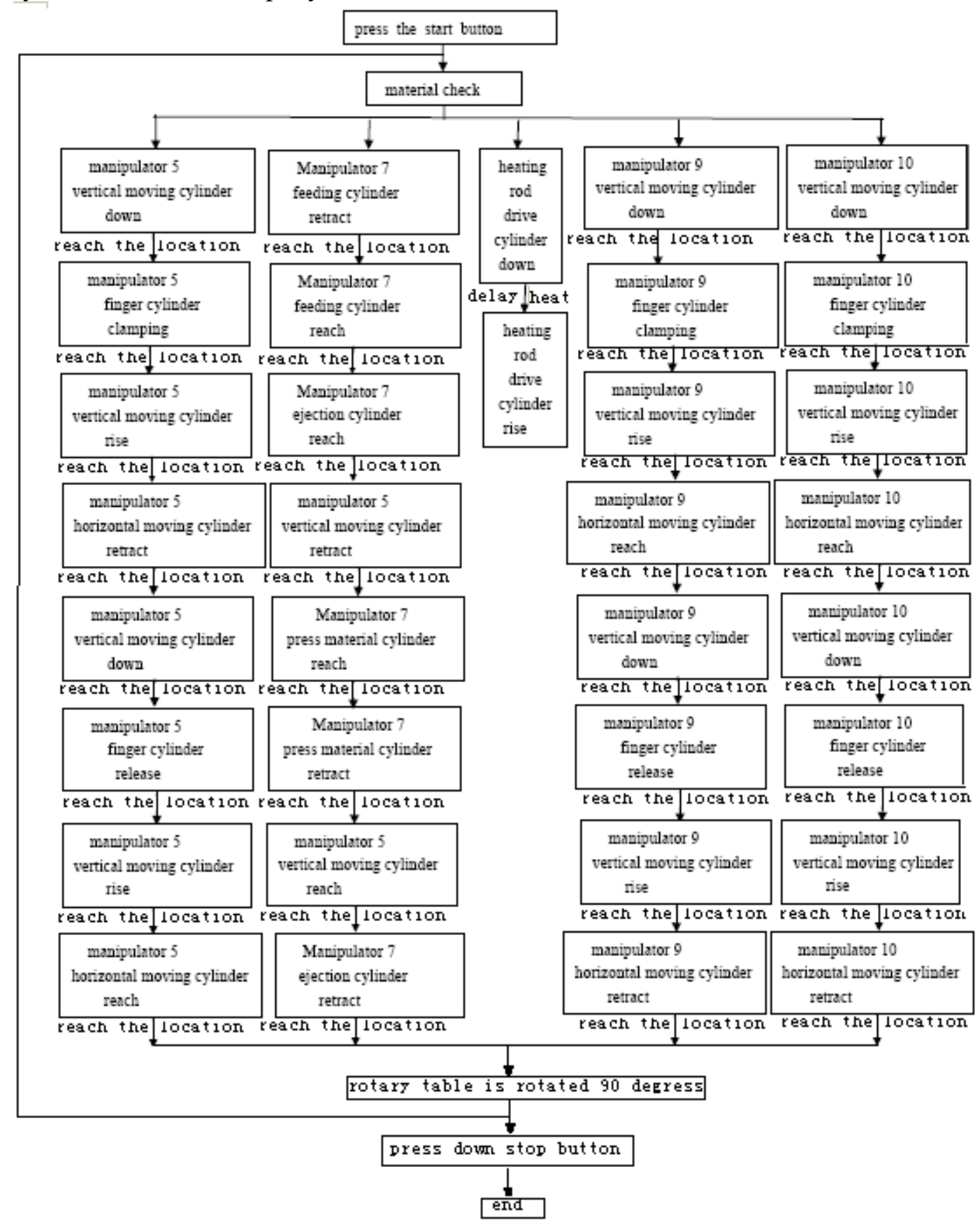

Fig. 5 Automatic circulation control flowchart of the equipment 


\section{References}

[1] Hoang, Nuong, Khon Loi Nguyen, and Bach Huynh Dunnigan. "Improvement of Outliers Detection Algorithm Based on Density." Journal of Applied Science and Engineering Innovation, Vol.4 No.3 (2017): 72-75.

[2] Liu, Ye, et al. "Matilda Floor Elevator PLC Control Circuit Design." International Journal of Advanced Pervasive and Ubiquitous Computing (IJAPUC) 9.1 (2017): 23-56.

[3] Li, Li, et al. "Design of Automatic Control System for Piggery Environment Based on Fuzzy Theory." Journal of Applied Science and Engineering Innovation, Vol.4 No.2 (2017): 46-50. 